\title{
RELIGIÃO E POLÍTICA NAS ELEIÇÔES AO LEGISLATIVO MUNICIPAL DE CAMPO MOURÃO, PARANÁ
}

\author{
Frank Antonio Mezzomo \\ Cristina Satiê de Oliveira Pátaro ${ }^{2}$ \\ Lara de Fátima Grigoletto Bonini ${ }^{3}$
}

\begin{abstract}
Resumo: Este artigo analisa as estratégias de campanha e o desempenho de cinco candidatos que declararam vínculo com instituiçōes religiosas por ocasião das eleições proporcionais no município de Campo Mourão-PR, em 2012. São analisados os materiais de campanha, além de entrevista realizada com cada um dos candidatos no momento que antecedeu a eleição. Dentre os resultados, destacam-se a conquista de vaga de suplência por quatro dos candidatos analisados e o êxito eleitoral de um deles, vinculado à Igreja Presbiteriana Renovada. Verificou-se ainda a recorrência a elementos religiosos nos discursos e materiais de divulgação, além do apoio das instituiçôes religiosas à candidatura de membros a ela vinculados. Os resultados sugerem uma aproximação e imbricação entre os campos político e religioso, presentes no contexto brasileiro.
\end{abstract}

Palavras-chave: Religião; Política; Eleições.

Abstract: This paper analyzes the campaign strategies and performances of five candidates who have declared links with religious institutions in the 2012 proportional elections of Campo Mourão-PR. It is analyzed campaign materials and interviews conducted with each candidate at the time preceding the election. Among the results, it was verified the successful election of one of them, linked to the Renewal Presbyterian Church, and the other four candidates was elected as substitutes. It was also observed the recurrence of religious elements in the discourses and campaign materials, besides the support of religious institutions to

1 Universidade Estadual do Paraná (Unespar). Campus de Campo Mourão, Brasil. Contato: frankmezzomo@gmail.com.

2 Universidade Estadual do Paraná (Unespar). Campus de Campo Mourão, Brasil. Contato: crispataro@gmail.com.

3 Universidade Estadual do Paraná (Unespar). Campus de Campo Mourão, Brasil. Contato:larascs@hotmail.com.

Debates do NER, Porto Alegre, ano I5, N. 25, P. 27I-289, JAN./Jun. 2014 
the candidacy of members linked to it. The results suggest an approach and overlap between the political and religious present in Brazilian context.

Keywords: Religion; Politics; Elections.

\section{INTRODUÇÃO}

Ao tematizar a presença de agentes ou atores religiosos nas eleições, coloca-se em pauta problemática tão cara às Ciências Sociais, a saber, a imbricação e permeabilização dos campos político e religioso, evidenciadas nos símbolos, valores e rituais cristãos presentes nos discursos e materiais de campanha dos candidatos políticos. Torna-se possível apontar as diversas inter-relações no âmbito da política e da religião, a influência de líderes religiosos e de poderes instituídos, como organizações partidárias e doutrinas espirituais, que permeiam os momentos eleitorais. Tais constataçôes implicam problematizar a noção de secularização e suas implicações no mundo contemporâneo.

Ao trazer à baila a questão da religião, em especial da participação e presença dos agentes religiosos na esfera da política, chama-se a atenção para o aspecto de que a compreensão da sociedade, das lógicas de poder e das estruturas sociais passam ou podem passar pelas interferências e imbricações próprias do campo religioso sobre/com o campo político. No que toca à compreensão desta problemática, parte da literatura, sobretudo no Brasil, tem apontado indícios que flagram a participação efetiva de agentes religiosos na política, assim como a recorrência à religião por parte de agentes políticos.

Neste artigo, buscamos compreender as relações estabelecidas entre os campos religioso e político com base em dados coletados por ocasião das eleições proporcionais de Campo Mourão ocorridas em 2012 . A ênfase do trabalho é analisar o desempenho eleitoral, o apoio institucional, o perfil e as estratégias de campanha adotadas por candidatos ao legislativo que mantêm algum tipo de vínculo com a religião.

4 Os dados discutidos neste artigo fazem parte de pesquisa mais ampla, desenvolvida com apoio do CNPq, intitulada Juventude, religião e política: compreensão das representaçôes politico-religiosas na campanha eleitoral e coordenada por Cristina Satiê de Oliveira Pátaro.

Debates do NER, Porto Alegre, Ano I5, N. 25, P. 27I-289, JAn./Jun. 2014 
Nesse sentido, a pesquisa parte de questionamentos que envolvem o lugar da religião na contemporaneidade, diante de mudanças e reconstruçôes que têm influenciado o cenário religioso atual, tais como a mobilidade de pertenças, a fluidez das identificações e a instabilidade dos agrupamentos religiosos. Desse modo, a partir dos indícios de ressignificações e deslocamentos, a religião passa a ser analisada sob novas perspectivas, como a da desregulação institucional (Hervieu-Léger, 2008, p. 21). A compreensão da desregulação institucional religiosa remete-nos ao fenômeno da secularização, a qual decorre do declínio da centralidade da religião enquanto instituição hegemônica de organização social, mesmo que não a apagando enquanto fenômeno social e enquanto opção e manifestação no nível da consciência individual (Ortiz, 2001; Sanchis, 1995; 1997; Berger, 2001).

No entendimento de Burity (2008), é arriscado reafirmar as constatações e projeções tradicionais das Ciências Sociais quanto ao declínio das práticas religiosas e da presença pública das religiōes. Ainda para o autor, o que se percebe é que o movimento da secularização não é uniforme e que, além disso, coexiste com os avanços na adesão ou prática religiosa, como também rivalizam entre si e/ou reforçam-se mutuamente (Butiry, 2008, p. 85). Há, assim, diálogos múltiplos entre a secularização e as manifestações religiosas, sendo possível especular sobre a dilatação e deslocamento das fronteiras do campo religioso, assim como a ressignificação de suas práticas (Burity, 2001, p. 28).

De forma análoga, Berger $(2001 ; 2004)$ também considera que a modernização não conduz necessariamente a um declínio da religião e que, em alguns casos, o que se observa é um rearranjo e ressignificações das crenças, práticas e instituições religiosas. $\mathrm{Na}$ esteira de tais considerações, pode-se afirmar que a religião não desaparece da sociedade, ao contrário, recompõe-se com novos fenômenos e representaçôes. Nesse processo, torna-se notável o pluralismo religioso, apresentado como uma das características das sociedades modernas, pela intensa movimentação de ideias e pessoas. Ainda conforme Berger, "[...] el pluralismo no cambia necesariamente lo que la gente cree, sino cómo lo cree" (Berger, 2004, p. 66), de modo que se observa o advento de novos movimentos religiosos, bem como a possibilidade de

Debates do NER, Porto Alegre, ANo I5, N. 25, P. 27I-289, JAn./Jun. 20 I4 
escolha e identificação com diversas formas de crença. A diversidade religiosa é, portanto, uma das características das sociedades modernas, uma vez que não existe uma religião absoluta capaz de se sobrepor às demais e se impor a toda a sociedade.

Nesse contexto está presente a problematização acerca da presença e dilatação das fronteiras dos campos político e religioso, e a consequente permeabilização entre ambos, pontualmente, aqueles surgidos no cenário religioso brasileiro. O trânsito religioso no Brasil foi legitimado e dinamizado pelo fenômeno da destradicionalização religiosa, processo em que a adesão, a filiação, as crenças e as práticas religiosas tornam-se uma questão de opção pessoal, voluntária e deliberada (Mariano, 2011, p. 247). Nesta perspectiva, a religião é vista como resultado de uma "escolha", uma vez que já não há obrigatoriedade, nem unicidade de "opçôes” religiosas. É nesse contexto que o pentecostalismo, especificamente, passa a se apresentar como uma variante de forte impacto (Burity, 2011, p. 73).

A sociologia da religião tem contribuído para compreender como nos últimos anos os evangélicos vêm se inserindo no campo político. $\mathrm{O}$ ativismo pentecostal na política partidária brasileira teria ocorrido sobretudo a partir da Assembleia Nacional Constituinte, eleita em 1986. Outrora, em grande medida, os evangélicos autoexcluíam-se da política, tida como mundana e diabólica, e realçavam seu apolitismo com o mote "crente não se mete em política". A justificativa para a adoção do novo lema corporativo, de que "irmão vota em irmão", passou a ser de que urgia defender os valores morais e os interesses institucionais das denominações evangélicas (Mariano, 2011, p. 250-251).

A participação das instituições e dos agentes religiosos na esfera política nacional inseriu um novo elemento para as campanhas políticas, sendo considerados de importância notável a participação e o apoio da estrutura religiosa nos pleitos eleitorais. Nesse sentido, Oro (2013) reitera que “[...] os políticos também reconhecem a força política que detém as organizações religiosas, mesmo na atualidade, levando-os a não desconsiderá-las em suas campanhas eleitorais." (Oro, 2013, p. 110). Compreensão semelhante é explorada por Machado (2006), ao indicar a religião como um fator que

Debates do NER, Porto Alegre, Ano I5, N. 25, P. 27I-289, JAn./Jun. 2014 
garante acesso à esfera política, o que se evidencia sobretudo no aumento da participação de evangélicos em processos eleitorais (Machado, 2006).

Observa-se, assim, que a presença de candidatos e parlamentares que portam o "selo" de denominações religiosas constitui elemento significativo nas recomposições dos imaginários sociais e nas novas configurações da política brasileira (Miranda, 2006). Entende-se, desse modo, que, ao contrário daqueles que vaticinaram o fim ou a privatização da religião, é possível afirmar que o campo religioso, assim como o campo político, passaram por ressignificações e deslocamentos, de modo a ser perceptível a confluência, o imbricamento e a permeabilização das fronteiras entre ambos.

\section{O DESENVOLVIMENTO DA PESQUISA}

O município de Campo Mourão localiza-se na Mesorregião Centro Ocidental do Paraná e possui uma população de mais de noventa mil habitantes (IBGE-Cidades, 2013). Conta com duas zonas eleitorais, uma delas abrangendo também os municípios de Farol e Luiziana, e a outra o município de Janiópolis. Na eleição de sete de outubro de 2012, concorriam às 13 cadeiras do legislativo municipal de Campo Mourão 161 candidatos, diante de um eleitorado de 64.967 pessoas $^{5}$.

$\mathrm{Na}$ análise das candidaturas homologadas pelo TRE-PR, identificamos diversos candidatos que possuíam algum tipo de vínculo com o campo religioso. Para este texto, foram selecionados cinco atores religiosos. Por atores ou agentes religiosos, entendemos, conforme Oro (2001), aqueles "[...] candidatos que reivindicaram abertamente a sua condição de líderes religiosos (membros da hierarquia ou participantes ativos de uma religião) ou que se apresentam como representantes de uma organização religiosa" (Oro, 2001, p. 10). De forma semelhante, Burity (2008) faz menção aos atores sociais e políticos, para os quais a identidade religiosa é ou se tornou um componente especialmente relevante. Por meio de tal compreensão,

5 Informações obtidas junto ao site do Tribunal Regional Eleitoral do Paraná. Disponível em: http://www.tre-pr.jus.br/. Acesso em: 20 out. 2013.

Debates do NER, Porto Alegre, ano I5, N. 25, P. 27I-289, JAn./Jun. 2014 
tornou-se possível identificar e analisar a presença de candidatos/atores religiosos que mantêm, formal ou informalmente, vínculos com as instituições religiosas presentes em Campo Mourão.

$\mathrm{Na}$ pesquisa em questão, a seleção dos atores religiosos indicados na Tabela 1 observou a ocorrência de ao menos um dos seguintes critérios: apoio de instituição religiosa; exercício de função vinculada à instituição eclesiástica (pastor, diácono, presbítero, ministro etc.); proximidade com o campo religioso, ainda que não tenha declarado abertamente a vinculação a uma determinada religião ${ }^{6}$.

Tabela 1- Eleição proporcional de Campo Mourão, 2012: candidato, filiação partidária, pertencimento religioso, quantidade de votos, situação eleitoral

\begin{tabular}{c|c|c|c|c}
\hline Candidato & Filiação Partidária & $\begin{array}{c}\text { Pertencimento } \\
\text { Religioso }\end{array}$ & $\begin{array}{c}\text { Qtd. } \\
\text { Votos }\end{array}$ & $\begin{array}{c}\text { Situação } \\
\text { Eleitoral }\end{array}$ \\
\hline $\begin{array}{c}\text { Anselmo } \\
\text { Camargo }\end{array}$ & $\begin{array}{c}\text { Partido } \\
\text { Republicano (PR) }\end{array}$ & $\begin{array}{c}\text { Igreja Adventista } \\
\text { do Sétimo Dia }\end{array}$ & 522 & Suplente \\
\hline $\begin{array}{c}\text { Pastor } \\
\text { Joaquim }\end{array}$ & $\begin{array}{c}\text { Partido da } \\
\text { Mobilização } \\
\text { Nacional (PMN) }\end{array}$ & $\begin{array}{c}\text { Igreja Evangélica } \\
\text { Só o Senhor é Deus }\end{array}$ & 124 & Suplente \\
\hline $\begin{array}{c}\text { Antônio } \\
\text { Freire Vieira }\end{array}$ & $\begin{array}{c}\text { Partido Trabalhista } \\
\text { Nacional (PTN) }\end{array}$ & $\begin{array}{c}\text { Igreja Presbiteriana } \\
\text { Renovada }\end{array}$ & 89 & Suplente \\
\hline Machado & $\begin{array}{c}\text { Partido } \\
\text { Republicano (PR) }\end{array}$ & $\begin{array}{c}\text { Igreja Presbiteriana } \\
\text { Renovada }\end{array}$ & 456 & Suplente \\
\hline $\begin{array}{c}\text { Toninho } \\
\text { Machado }\end{array}$ & $\begin{array}{c}\text { Partido } \\
\text { Republicano (PR) }\end{array}$ & $\begin{array}{c}\text { Igreja Presbiteriana } \\
\text { Renovada }\end{array}$ & 685 & Eleito \\
\hline
\end{tabular}

Para a realização da pesquisa, foram coletados os materiais de campanha dos candidatos, tais como matérias publicadas em jornais, panfletos, santinhos e flyers, programas transmitidos em horário eleitoral obrigatório, notas publicadas na imprensa local e regional fazendo menção às candidaturas, além de dados obtidos junto à Justiça Eleitoral, como informações pessoais

6 Vale destacar que alguns candidatos expressam claramente o seu pertencimento religioso e outros, embora não se declarando oficialmente, fizeram uso de concepçôes, mensagens e apropriações discursivas que compõem o universo simbólico e podem produzir efeitos de sentido junto aos eleitores.

Debates do NER, Porto Alegre, Ano I5, N. 25, P. 27I-289, JAn./Jun. 2014 
dos candidatos e o quantitativo de votos obtidos em cada uma das zonas e seçôes eleitorais.

Além das fontes coletadas, realizou-se entrevista semiestruturada com cada um dos candidatos, no período antecedente ao pleito eleitoral, durante os meses de agosto e setembro de 2012. As entrevistas são consideradas importantes fontes que possibilitam o estudo da história do tempo presente a partir da relação intrínseca entre o pesquisador e a testemunha (Borges, 2012). Nesse sentido, por meio desse procedimento metodológico, buscou-se identificar a trajetória política e religiosa do candidato, o pertencimento e a vinculação à instituição religiosa, os apoios recebidos, a concepção de política e as estratégias de campanha utilizadas.

O material produzido e coletado permitiu registrar não somente o evento das eleiçôes, ocorrido em sete de outubro de 2012, como o desenvolvimento da campanha realizada oficialmente desde trinta de junho daquele ano, conforme calendário eleitoral.

\section{AGENTES RELIGIOSOS NA CAMPANHA AO LEGISLATIVO MUNICIPAL EM CAMPO MOURÃO}

Passamos agora à apresentação e discussão dos dados referentes a cada um dos candidatos pesquisados, buscando compreender as intersecções entre os campos religioso e político, por ocasião da campanha ao legislativo municipal de Campo Mourão, em 2012. Na análise do material, buscou-se evidenciar a relação dos candidatos com o campo religioso, sua atuação e abrangência da campanha, além da utilização das representaçôes religiosas como estratégia de convencimento no pleito eleitoral ao legislativo municipal.

Anselmo Júnior Camargo concorreu ao legislativo municipal de Campo Mourão pelo Partido da República (PR) e possui vínculo com a Igreja Adventista do Sétimo Dia. É natural de Campo Mourão, bacharel em direito, trabalha em uma empresa de assessoria em serviços jurídicos e pela primeira vez participou do pleito eleitoral.

Nas propagandas eleitorais, o candidato não declarou seu pertencimento religioso, e seus santinhos continham slogans que remetiam à juventude. $\mathrm{Na}$

Debates do NER, Porto Alegre, ano I5, N. 25, P. 27I-289, Jan./Jun. 2014 
mensagem veiculada no horário eleitoral, Anselmo Camargo declarava seu compromisso em desenvolver um mandato participativo com a população, movimentos sociais e entidades comunitárias.

As estratégias de campanha concentraram-se em reuniões diárias nas residências, nos bairros periféricos e também nas empresas, tendo ainda se utilizado de adesivos, banners e perfurades, além do apoio de amigos e conhecidos que auxiliaram na divulgação das propostas.

Apesar de frequentar o templo localizado no bairro Cohapar, região oeste de Campo Mourão, é frequentemente convidado a orar em outros templos adventistas do município, demonstrando sua articulação com fiéis de outros bairros e localidades. Quando perguntado se a instituição religiosa manifesta apoio à sua candidatura, Anselmo Camargo declarou que recebe apoio dos membros, porém esclarece que "[...] A igreja em si é neutra”.

O candidato ainda explicou que exerce funçôes diversificadas na Igreja, mantendo-se envolvido com as atividades da instituição. Caso eleito, pretendia expandir para o município alguns projetos realizados na Igreja, como a conscientização acerca da violência contra a mulher e projetos voltados para a juventude. Declarou ainda a intenção de apresentar um projeto de lei para que as instituições públicas e privadas passem a respeitar os adventistas no que tange à observância do sábado como dia de repouso e culto. Verifica-se, assim, a imbricação político-religiosa do candidato a vereador, ao intencionar estender princípios de cunho religioso à esfera pública. Nesse caso, observa-se que o candidato pretende se utilizar da prática política com vistas a atender uma especificidade exclusiva de sua religião.

Anselmo Camargo afirmou que o vínculo religioso que mantém com a Igreja Adventista do Sétimo Dia influenciará suas decisões no possível mandato legislativo, pois entende que "Todo homem religioso tem que levar seus princípios com ele onde quer que vá" (Camargo, Anselmo. Entrevista). Pode-se observar, assim, que o agente religioso faz uso de um recurso adicional em sua candidatura, de modo que os princípios religiosos são utilizados para suscitar a confiança dos eleitores, afinal, como destaca Novaes (2001, p. 61): “[...] a política não é feita apenas de razão prática, não há política sem símbolos, vários recursos do fazer político provêm do campo religioso”.

Debates do NER, Porto Alegre, Ano I5, N. 25, P. 27I-289, JAn./Jun. 2014 
Anselmo Camargo obteve, em 2012, um total de 522 votos, conquistando vaga de suplente.

Pastor Joaquim é ministro evangélico e pastor da Igreja Só o Senhor é Deus e, na eleição de outubro de 2012, foi candidato pelo Partido da Mobilização Nacional (PMN). É natural de Euclides da Cunha-SP e possui o Ensino Fundamental incompleto. Participou pela segunda vez do pleito eleitoral, sendo a primeira em 2008, pelo Partido da República (PR), ocasião em que não foi eleito (Mezzomo; Bonini, 2011).

Apesar de experiências recentes no pleito eleitoral, Pastor Joaquim declarou, na entrevista concedida, que sua relação com a política ocorre desde a juventude, tendo inclusive algumas interaçóes junto ao legislativo de Quirinópolis-GO, em momentos de oração e leitura bíblica com os vereadores.

Durante sua campanha, em 2012, fez uso, nos materiais distribuídos e em apariçôes públicas, das tradicionais "vestes de santo": sapato social, terno e gravata (Mariano, 2003). No programa eleitoral obrigatório, saudava o eleitor com a expressão "Que a paz do Senhor esteja adentrando em todo lar mourãoense", apresentando-se como pastor e candidato, e finalizando com a frase "Vote com amor, vote no pastor". Nos demais materiais de campanha, destacavam-se a função religiosa exercida, bem como o uso de mensagens religiosas recorrendo a expressóes como "amor" e "paz do Senhor".

Por meio do acionamento de uma plêiade de estratégias, dispositivos e instrumentos na disputa político-eleitoral, Pastor Joaquim utilizou-se da panfletagem de santinhos, placas e adesivos nos carros, os perfurades. Concentrou-se em uma "estratégia espiritual, pastoral", a partir de conversas com amigos, conhecidos e membros da Igreja. Declarou que a Igreja Só o Senhor é Deus manifestou apoio à sua candidatura, tendo, sobretudo, apoio do presidente mundial da instituição religiosa, cuja sede encontra-se no município de Maringá-PR, a noventa quilômetros de Campo Mourão.

O discurso do candidato é permeado de referências bíblicas e alusões religiosas, que o colocariam em uma condição diferenciada dos demais candidatos: “[...] nós temos que mostrar pra que nós somos candidatos [...], porque mesmo na escuridão muitas vezes nós temos que brilhar como

Debates do NER, Porto Alegre, ano I5, N. 25, P. 27I-289, Jan./Jun. 2014 
servos de Deus, e só focando na verdade" (Joaquim, Pastor. Entrevista). A este respeito, Santos (2008) afirma que:

[...] a grande referência está no âmbito religioso. A Bíblia e todos os simbolismos nela contidos devem ser as fontes de orientação para aqueles que desejam seguir pelo caminho "correto". O imaginário religioso é, desta maneira, acionado para avaliar os comportamentos dos agentes políticos, servindo como medida daquilo que é tido ou não como correto e, principalmente, justificando os porquês da inserção de um pastor pentecostal na atividade política. (Santos, 2008, p. 209).

É também possível identificar demandas do campo religioso nas propostas eleitorais do candidato, ao sugerir, por exemplo, a construção de um ambiente apropriado para a prática do batismo, ou, ainda, de um local para a realização de festas e eventos cristãos. Nesse ponto, alguns autores destacam que diversas religiões acabam por ingressar no campo político ao reconhecerem a importância deste último para ampliar sua atuação na sociedade e obter benefícios do Estado (Oro, 2013; Machado, 2003).

$\mathrm{Na}$ eleição proporcional de 2012, Pastor Joaquim conquistou 124 votos, obtendo vaga de suplente.

Os demais agentes religiosos analisados por esta pesquisa são candidatos a vereadores vinculados à Igreja Presbiteriana Renovada.

Antonio Freire Vieira concorreu à eleição de 2012 pelo Partido Trabalhista Nacional (PTN). Possui o Ensino Médio completo e desenvolve serviços de contabilidade. Participou, em 1976 e em 1994, de pleitos eleitorais ao legislativo do município de Janiópolis-PR, localizado a aproximadamente 45 quilômetros de Campo Mourão, não tendo sido eleito.

Na propaganda transmitida no horário eleitoral durante a campanha, o candidato enfatizava ser natural de Campo Mourão, portador de deficiência física e assumia o compromisso com a verdade na política. Como estratégia de campanha, utilizou mensagens veiculadas em carro de som e placas nas ruas, além das tradicionais reunióes e visitas a famílias. Embora o candidato não tenha apresentado seu vínculo com a Igreja Presbiteriana Renovada, pudemos identificar no material de campanha mensagens religiosas fazendo alusão a passagens bíblicas.

Debates do NER, Porto Alegre, Ano I5, N. 25, P. 27I-289, JAn./Jun. 2014 
Antonio Freire Vieira frequenta a Igreja Presbiteriana Renovada localizada no bairro Jardim Santa Cruz, região leste de Campo Mourão, onde também já exerceu a função religiosa de diácono. Atualmente, é diretor do Grupo Evangelismo de Rua (GedR), um projeto voltado para a evangelização bíblica. Segundo o agente religioso, o pastor da Igreja na qual participa manifestou concordância com sua candidatura, havendo, portanto, o apoio e a probabilidade de votos dos membros-irmãos. Quanto à maneira de fazer política, pretendia atingir o eleitor consciente, declarando que a verdadeira campanha eleitoral, no sistema democrático, deve ser realizada sem o "voto sujo", isto é, o oferecimento de recompensas para a conquista do eleitor (Vieira, Antonio Freire. Entrevista).

O discurso do candidato recorre aos princípios cristãos como um diferencial no contexto da política, em geral marcada pela corrupção. Afirma o candidato: "Se tiver temor a Deus não se corrompe [...] porque a corrupção não é de Deus, a Bíblia não ensina ninguém a ser corrupto." (Vieira, Antonio Freire. Entrevista). A este respeito, Maia (2006, p. 107) reitera a tentativa de sacralização do espaço político, por ser considerado um espaço em que imperam atitudes de realização de prazeres individuais. Nesta guerra santa, os evangélicos propõem-se a limpar toda e qualquer impureza que está presente na esfera da política.

$\mathrm{Na}$ eleição de 2012, Antonio Freire Vieira obteve 89 votos, conquistando vaga de suplente.

O segundo agente religioso vinculado à Igreja Presbiteriana Renovada é Raimundo Machado, tendo registrado sua candidatura como Machado. Filiado ao Partido da República (PR), é aposentado e pela terceira vez participa da disputa ao legislativo municipal. Na eleição de 2004, conquistou a suplência pelo Partido da Social Democracia Brasileira (PSDB), e no ano de 2008, candidatou-se novamente, não sendo eleito (Mezzomo; Bonini, 2011).

Em seu material de campanha, Machado apresentava um breve histórico de funções exercidas, tais como presidente de conselho municipal e presbítero da $1^{\text {a }}$ Igreja Presbiteriana Renovada. Constava ainda em seus santinhos a mensagem religiosa de benção, bem como o pedido do voto aos irmãos e amigos. A denotação religiosa surge, neste contexto, com práticas

Debates do NER, Porto Alegre, ano I5, N. 25, P. 27I-289, Jan./Jun. 2014 
e adjetivos que remetem a categorias de benção, justiça, paz, entre outros, exaltando ações positivas, que motivem a confiança dos eleitores.

Outras formas de articulação também foram utilizadas na sua campanha. Machado declarou possuir o apoio dos pastores da instituição religiosa, participar dos cultos nos quais sua candidatura era apresentada e de reuniōes da igreja nas quais distribuía seu material de campanha. Afirmou possuir vínculos com demais Igrejas Presbiterianas do município, contando com o apoio e votos desses membros, "Eu procuro estar participando com eles, do culto, e ali eu sou apresentado, depois eu tenho a oportunidade lá fora de estar distribuindo meu material, conversando" (Machado, Raimundo. Entrevista). Tais articulações, promovidas pelo agente religioso junto às Igrejas e seus fiéis, vão ao encontro do entendimento de Maia (2006, p. 107), para quem a alta participação dos evangélicos em cultos e atividades possibilita uma maior exposição e legitimidade ao discurso apresentado pelas lideranças, justificando a relevância das aproximações entre a política e a religião.

No que tange às intenções do candidato, constava, dentre suas propostas de campanha, a proposição de lei que oficializasse uma data comemorativa dos evangélicos, como um dia gospel, justificando que esse grupo religioso não possui a devida atenção do poder público ${ }^{7}$.

$\mathrm{Na}$ eleição proporcional de 2012, Machado obteve vaga de suplente, com 456 votos.

Toninho Machado, terceiro candidado ligado à Igreja Presbiteriana Renovada, concorreu à eleição pelo Partido da República (PR), possui o Ensino Médio e é servidor público municipal. Participou pela segunda vez do pleito eleitoral, sendo que na primeira, em 2004, concorreu pelo Partido Trabalhista Brasileiro (PTB) e ficou como terceiro suplente. Durante o programa eleitoral obrigatório, mencionava que atuou como presidente de bairro e anunciava alguns compromissos políticos como: defesa dos

7 Sobre tal contexto, cabe apontar que em Farol-PR, distante 27 quilômetros de Campo Mourão, pela Lei no 539 de 2010 instituiu-se o "Dia Municipal do Evangélico", constando no Calendário Oficial de Eventos do Município. Disponível em: http://www. farol.pr.gov.br/. Acesso em 10 set. 2013.

Debates do NER, Porto Alegre, Ano I5, N. 25, P. 27I-289, JAn./Jun. 2014 
servidores públicos, atuação em favor da população e melhorias em todos os segmentos sociais.

Seu material de campanha consistia de santinhos e cartas de apresentação direcionadas. Nas propagandas distribuídas nos bairros e na região periférica do município, o candidato enaltecia ações realizadas quando da sua atuação como presidente do bairro Jardim Pio XII, região oeste de Campo Mourão, no período de 2010 a 2012. Já nas cartas eleitorais distribuídas aos irmãos religiosos, Toninho Machado apresentava-se como presbítero, membro da 2a Igreja Presbiteriana Renovada desde 1988, declarando contar com o apoio moral e espiritual do Conselho Administrativo dessa Igreja. Entendemos, com base em Santos (2008), que os discursos produzidos durante a campanha eleitoral podem variar conforme o ambiente no qual são veiculados, podendo haver uma divisão entre o que deve ser dito "dentro" e "fora" da instituição religiosa, acionando-se símbolos e discursos diferentes de acordo com a situação e o público que se quer atingir.

Toninho Machado realizou, em sua campanha, visitas às residências e às empresas. Apresentou ainda uma estimativa de votos provenientes de amigos e conhecidos do local onde trabalha, no Departamento de Vigilância Municipal. Contudo, explicou que seu reduto eleitoral concentrava-se nas instituiçôes religiosas, onde contava com compromisso de apoio e voto tanto dos membros quanto dos pastores, tendo em vista que "O Conselho Administrativo das Igrejas está fechado comigo” (Machado, Toninho. Entrevista).

O candidato, por fim, declarou grande expectativa quanto à sua eleição, tendo em vista a estratégia de criar bases eleitorais em diferentes bairros do município, afirmando: "Eu estou fazendo política dentro de uma grande possibilidade de eleição". Toninho Machado obteve 685 votos e conquistou a décima segunda vaga de vereador.

\section{A CAMPANHA ELEITORAL E AS APROXIMAÇÕES ENTRE POLÍTICA E RELIGIÃO}

A partir dos dados referentes à campanha eleitoral dos candidatos analisados no presente texto, podemos verificar imbricaçóes entre os campos

Debates do NER, Porto Alegre, ano I5, N. 25, P. 27I-289, Jan./Jun. 2014 
político e religioso, reforçando a ideia de que "[...] a religião e os valores religiosos não podem ser desprezados e sua apropriação discursiva visa produzir efeitos de sentido junto aos eleitores portadores de mentalidade religiosa" (Oro, 2001, p. 64). Nesse sentido, a campanha é dirigida no intuito de alcançar o maior número de votos e cada candidato realiza um trabalho midiático diferenciado, evidenciando maior ou menor ênfase ao pertencimento religioso.

A utilização de mensagens religiosas e trechos bíblicos no material de campanha confere para o ato de votar, de alguma forma, um sentido que não está restrito exclusivamente à motivação de cumprir o dever cívico, mas que se refere à defesa de princípios cristãos como o acesso ao bem comum, à justiça social, à igualdade, entre outras razões que engrossam a retórica política. Para Steil (2001, p. 81), o voto em um candidato apresentado como agente religioso "[...] confere aos fiéis uma positividade que não encontramos naqueles que inscrevem o exercício do voto no campo da racionalidade política”. Vale destacar que, conforme apresentamos anteriormente, alguns candidatos expressam claramente o seu pertencimento religioso e outros, embora não se declarando como agentes religiosos, fazem uso de concepções, mensagens e apropriações discursivas que compõem o universo simbólico da religião.

Cada Igreja difere em pontos doutrinais e nas alternadas formas de celebração ritual, porém todas possuem um carisma institucional, que pode ser utilizado nos momentos dos pleitos eleitorais por elas mesmas ou pelos agentes religiosos a ela associados. Esse carisma torna-se um recurso à disposição, embora que "[...] a maneira e a intensidade com que cada igreja vai se apropriar dele depende de seus mitos de origem, de suas trajetórias históricas e da forma como elas vão se posicionar nas disputas" (Steil, 2001, p. 76-77).

Os candidatos à vereança no pleito de 2012, em Campo Mourão, analisados neste texto, pertenciam às denominações religiosas Igreja Só o Senhor é Deus, Igreja Adventista do Sétimo Dia e Igreja Presbiteriana Renovada, o que demonstra a diversificada participação religiosa na vida político-partidária do município, evidenciando diferentes configuraçóes no cenário político e religioso. $\mathrm{O}$ apoio das instituições religiosas aos cinco candidatos pesquisados 
ocorreu de diversas maneiras, com maior ou menor intensidade. Ressalta-se que todos os candidatos estudados declararam receber apoio de suas Igrejas, seja do presidente institucional, do pastor ou dos membros. Alguns agentes religiosos afirmaram, ainda, a inter-relação com diversas denominações religiosas ou com demais congregações de diferentes bairros no município.

Dos cinco atores religiosos pesquisados, quatro obtiveram vaga de suplência no processo eleitoral e um conquistou uma das treze vagas disputadas pelos 161 candidatos. Entende-se, assim, que as mensagens religiosas utilizadas na campanha eleitoral podem produzir efeitos de sentido a fim de obter convencimento do eleitor, embora não garantam a eficácia política desejada.

A partir dos dados analisados, pode-se identificar as imbricações e a permeabilização das fronteiras entre religião e política basicamente em três diferentes movimentos. $\mathrm{O}$ primeiro deles refere-se à recorrência dos candidatos a elementos vinculados à religião, tais como o uso de vestes de santo, das passagens bíblicas e de expressóes e discursos religiosos. Em um segundo caso, verifica-se nas propostas dos candidatos a existência de uma pauta voltada para as demandas próprias das instituições religiosas, como a observância do sábado para os adventistas, a construção de um local para realização de eventos cristãos e a oficialização de data comemorativa dos evangélicos. Por fim, percebe-se que os candidatos tendem a se aproximar do campo religioso como forma de ampliar seu potencial eleitoral. Tais movimentos evidenciam uma dinâmica de inter-relação e apropriação mútua entre as esferas política e religiosa.

É possível ainda afirmar que há uma ligação entre a forma de organização, o modelo institucional adotado pela religião e o resultado das eleições, sem, contudo, desconsiderar o processo da identificação pessoal e das trajetórias individuais de candidatos e eleitores. Para Novaes (2001, p. 77), mesmo que " $[. .$.$] as possibilidades de sucesso de candidatos evangélicos dependam,$ também, das experiências pessoais e de outros vínculos políticos que cada fiel-eleitor possa ou não ter paralelamente, 'ser evangélico' tornou-se uma nova variável. Uma importante variável entre outras que configuram as relaçôes entre campo político e no campo religioso".

Debates do NER, Porto Alegre, ano I5, N. 25, P. 27I-289, Jan./Jun. 2014 
Em relação ao agente religioso pesquisado que conquistou êxito eleitoral, pertencente à Igreja Presbiteriana Renovada, podemos recorrer a Miranda (2006), ao afirmar que a eleição de um agente religioso proporciona nova dinâmica aos movimentos político-partidários, pois implicam uma convivência de lideranças distintas. A pesquisadora ainda assinala que a legitimação das lideranças religiosas se estende às pretensões políticas, pois os fiéis reconhecem os candidatos da igreja como merecedores de confiança, porque "são de Deus".

$\mathrm{Na}$ campanha eleitoral investigada, percebem-se narrativas com uma diversidade de percepções, tanto político-ideológicas quanto religiosas. Destaca-se que os candidatos assumiam discursos e propostas que remetiam à vivência e às instituições religiosas. Santos (2008) compreende que a intenção seria, de certa forma, fazer do espaço do parlamento uma extensão do púlpito, no sentido de garantir a possibilidade de a Igreja contar com um dos "seus" quando precisar de qualquer tipo de intervenção ou subsídio junto ao poder público.

A presença do fenômeno religioso na esfera pública, tematizada neste artigo, vem sendo discutida na esfera tanto da Sociologia quanto das Ciências Políticas, da História, dentre outros. Neste contexto, a pesquisa aqui apresentada buscou problematizar as imbricaçóes entre os campos político e religioso, por meio da análise da participação de atores religiosos nas eleições de 2012, em Campo Mourão, explorando aspectos relacionados às diferentes performances dos candidatos e à recorrência a elementos religiosos como estratégia de campanha. O que se pode apontar, com base nos dados analisados, é que a conceituação e as implicações da imbricação entre os campos político e religioso, assim como o fenômeno da secularização devem ser repensados/ rediscutidos a partir de novas pesquisas, em vista de compreender as novas configurações dos campos religioso e político brasileiros. 


\section{REFERÊNCIAS}

BERGER, Peter Ludwig. Globalización y religión. Iglesia Viva. Valencia. n. 218, abr./jun. 2004. Disponível em: http://www.iglesiaviva.org/218/218-31-DEBATE.pdf. Acesso em: 10 set. 2013.

. A dessecularização do mundo: uma visão global. Revista Religião e Sociedade. Rio de Janeiro, v. 21, n. 1, p. 9-23, abr. 2001.

BORGES, Viviane Trindade. As falas gravadas pelos outros: fontes orais, arquivos orais e arquivos sonoros, inquietações da história do tempo presente. Revista Diálogos, Maringá, v. 16, n. 2, p. 663-676, maio/ago. 2012.

BURITY, Joanildo. Fé na revolução: protestantismo e o discurso revolucionário brasileiro (1961-1964). Rio de Janeiro: Novos Diálogos, 2011. n. 2, 2008 .

Religião, política e cultura. Revista Tempo Social, São Paulo, v. 20,

Religião e política na fronteira: desinstitucionalização e deslocamento numa relação historicamente polêmica. Revista de Estudos da Religião, São Paulo, n. 4, p. 27-45, 2001.

CAMARGO, Anselmo. Entrevista. Campo Mourão, 11 set. 2012. (A/A).

HERVIEU-LÉGER, Danièle. Peregrino e o convertido: a religião em movimento. Petrópolis: Vozes, 2008.

INSTITUTO BRASILEIRO DE GEOGRAFIA E ESTATÍSTICA Cidades. Disponível em: http://cidades.ibge.gov.br. Acesso em: 17 out. 2013. JOAQUIM, Pastor. Entrevista. Campo Mourão, 28 ago. 2012. (A/A).

MACHADO, Maria das Dores Campos. Política e religiāo: a participação dos evangélicos nas eleições. Rio de Janeiro: FGV, 2006.

. Existe um estilo evangélico de fazer política? In: BIRMAN, Patrícia (Org.). Religião e espaço público. Brasília: Attar Editorial, 2003. p. 283-307. MACHADO, Raimundo. Entrevista. Campo Mourão, 14 set. 2012. (A/A).

Debates do NER, Porto Alegre, ano I5, N. 25, P. 27I-289, Jan./Jun. 2014 
MACHADO, Toninho. Entrevista. Campo Mourão, 05 set. 2012. (A/A). MAIA, Eduardo Lopes Cabral. Os evangélicos e a política. Revista Em Tese, Florianópolis, v. 2, n. 2 (4), p. 91-112, ago./dez. 2006.

MARIANO, Ricardo. Guerra espiritual: o protagonismo do diabo nos cultos neopentecostais. Debates do NER. Porto Alegre, ano 4, n. 4, p. 21-23, jul. 2003.

. Laicidade à brasileira. Católicos, pentecostais e laicos em disputa na esfera pública. Civitas, Porto Alegre, v. 11, n. 2, p. 238-258, maio/ago. 2011.

MEZZOMO, Frank Antonio; BONINI, Lara de Fátima Grigoletto. O religioso em contexto político-eleitoral: eleições proporcionais de Campo Mourão/PR. Revista Brasileira de História das Religiōes, Maringá, v. 4, p. 183-204, 2011.

MIRANDA, Júlia. O candidato da igreja: do que nos fala a sua presença na política brasileira. In: LEMENHE, Maria Auxiliadora; CARVALHO, Rejane Vasconcelos Accioly (Orgs.). Política, cultura e processos eleitorais. Fortaleza: Fundação Konrad Adenauer, 2006.

NOVAES, Regina. A divina política. Notas sobre as relações delicadas entre religião e política. Revista USP, São Paulo, n. 49, p. 60-81, mar./maio 2001.

ORO, Ari Pedro; CARVALHO JUNIOR, Erico Tavares de. Religiōes e eleições 2012 em Porto Alegre. Debates do NER, Porto Alegre, ano 14, n. 23, p. 109-144, jan./jun. 2013.

Religião e política nas eleições 2000 em Porto Alegre. Debates do NER, Porto Alegre, ano 2, n. 3, 2001.

ORTIZ, Renato. Anotações Sobre Religião e Globalização. Revista Brasileira de Ciências Sociais, São Paulo, v. 16, n. 47, out. 2001.

SANCHIS, Pierre. O campo religioso contemporâneo no Brasil. In: ORO, Ari Pedro; STEIL, Carlos Alberto (Orgs.). Religião e Globalização. Petrópolis: Vozes, 1997. 
O campo religioso será ainda hoje o campo das religióes? In: HOORNAERT, Eduardo (Org.). História da Igreja na América Latina e no Caribe (1945-1995): o debate metodológico. Petrópolis: Vozes, 1995.

SANTOS, Marcio Martins dos. “Tribunos do povo, servos de Deus": Um estudo antropológico sobre políticos e religião na cidade de Porto Alegre. Revista Anthropológicas, São Paulo, ano 12, v. 19. n.1 , p. 201-239, 2008.

STEIL, Carlos Alberto. Eleições, voto e instituição religiosa. Debates do NER, Porto Alegre, ano 2, n. 3, set. 2001.

TRIBUNAL REGIONAL ELEITORAL DO PARANÁ - TRE/PR. Zonas eleitorais. Disponível em: http://www.tre-pr.jus.br/institucional/zonas-eleitorais/zonas-eleitorais-tre-pr-pesquisa-por-municipio-1. Acesso em: 10 set. 2013.

. Resultado eleições municipais. Disponível em: http://www.tre-pr. jus.br/eleicoes/resultados/resultados-de-eleicoes-municipais-tre-pr. Acesso em: 10 set. 2013.

VIEIRA, Antônio Freire. Entrevista. Campo Mourão, 04 set. 2012. (A/A).

Recebido em 01/11/2013

Aprovado em 20/04/2014.

Debates do NER, Porto Alegre, ano I5, N. 25, P. 27I-289, JAn./Jun. 2014 